Peer-Reviewed Article
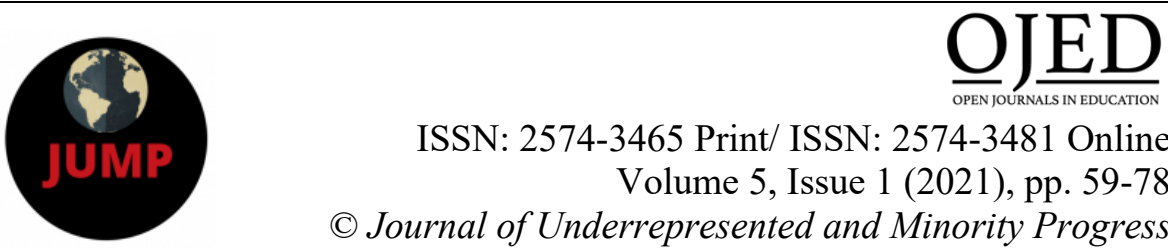

ISSN: 2574-3465 Print/ ISSN: 2574-3481 Online

Volume 5, Issue 1 (2021), pp. 59-78

(C) Journal of Underrepresented and Minority Progress

http://ojed.org/jump

\title{
Diversity in STEM: A Look at STEM Choices Amongst Black and Latinx High School Students
}

\author{
Michael Owens \\ Natasha Ramsay-Jordan \\ University of West Georgia, USA
}

\begin{abstract}
The calls for increased diversity and participation of persons from historically underrepresented groups in science, technology, engineering and math (STEM) have gained increasing prominence within education in recent years, yet Black and Latinx students continue to have unequal opportunities to pursue STEM. This research investigates the disparity of Blacks and Latinx students' participation within high school STEM. Specifically, systemic influences and teacher impact are discussed. The research identifies teacherstudent relationships, student recruitment methods, teachers' perceptions about STEM, inadequate preparation of teachers, and lack of resources as stimuli that inhibit student participation within STEM courses and programs. The examination of these stimuli could help school leaders and educators implement appropriate strategies to increase participation rates of Blacks and Latinx in STEM.
\end{abstract}

Keywords: Black Students, Historically Marginalized Groups, Minoritized Students, Latinx Students, STEM 


\section{INTRODUCTION}

At the turn of the century, U.S. leaders began to encourage states to focus on enhancing the instruction of science, math, technology, and engineering within schools. The emphasis of grouping the quartet of disciplines became known as SMET, subsequently amended to STEM in the 21st Century (Burrows et al., 2018). The interrelated groupings of the four STEM subjects into the secondary education school curriculum, meant students would graduate high school with the necessary problem-solving skills to capitalize on the workforce's trends (Idin \& Donmez, 2018). The enhanced education would enable students to become competitive and thrive within a demanding labor pool, ensuring America's strength within the global economy (Stevenson, 2014).

However, the existing collection of proficient STEM candidates fail to compliment the STEM job growth and accumulating demands, resulting in limitations of innovation and economic development (Mau et al., 2019). According to Mau et al. (2019), the STEM labor force expansion is vital to economic growth in many developing countries. Recent data from the United States Bureau of Labor Statistics (2021) projects an 8.8\% increase in STEM occupations from 2018 through 2028. With the projected increase in STEM fields, the pool of qualified applicants must continue to be amassed and diversified to the labor force (Slovacek et al., 2019). A diversified STEM field could help fill the surplus of available jobs, escalate the global economy, and encourage innovative ideas through increased diversity within the area (Stevenson, 2014). Making the underrepresentation for students from historically minoritized groups including Black, Latinx, and women in STEM a great concern (Lyon et al., 2012) and the need to examine factors impacting their STEM involvement critical (Elliott, 2015).

Notably, although many strategies are used to ensure that each child receives an equitable education, schools serving predominantly Black and Latinx students continue to experience inadequate and inequitable schooling experiences (Darling-Hammond, 2010; Ostrander, 2015). Many of these experiences are often rooted in historical practices and connect to student's socioeconomic status. Continued historical and systemic inequitable practices, including access to adequate and sufficient community resources, race-related matters, funding, and high-quality teachers, influence the STEM choices of Black and Latinx students. While this increasing shortage of Blacks, Latinxs, and women in STEM fields might not be wished for, it is nonetheless the de facto outcome. Expectedly, this actual outcome has led to many questions and concerns about the reasons for the inequitable educational 
experiences of African American students and why this growing racial gap in STEM is expected to increase?

The literature review explores scholarship addressing systemic and teacher influences impacting the underrepresentation of marginalized populations such as Blacks, Latinxs, and women in STEM. Then, the implications and conclusion sections contribute to the understanding and discussion of what could be done to increase participation of these underrepresented groups in STEM by focusing on best practices that could reduce students' alienation from these groups within the field. Specifically, the implications of this review center on teacher-related influences and systemic influences in STEM careers. There is a lack of literature discussing teacher-student relationships and systemic differences as primary focuses for closing the STEM gap. This literature review is the type of investigative work needed for researchers and practitioners to understand better and address the lack of diversity in STEM. What follows is a brief discussion about systemic practices and teacher influences as impactful factors of historically underrepresented populations in STEM courses. Specifically, the authors explore the experiences of Black and Latinx students at the intersection of systemic impacts and teachers' impact as primary stimuli for students enrolling in and participating in STEM programs. Afterward, the authors draw on the literature to suggest rethinking ways of increasing the STEM engagement of Black and Latinx students and further improving their STEM choices in high school.

\section{REVIEW OF LITERATURE}

For years, there has been a consistently deteriorating population within STEM education at the high school level. Although there is a lack of STEM participation across all demographics, there is a significant deficiency of historically minoritized groups within the field (Lyon et al., 2012). Research scholars believe that by increasing the number of underrepresented students within the field, the STEM domain will be significantly enriched. The fundamental influences that cause the underrepresentation of minoritized students in STEM fields include gender stereotypes and biases, self-efficacy, student interests, course selection, academic proficiencies, and familial background (Wang \& Degol, 2017; Mau et al., 2019).

Even with abundant literature addressing the disparity in students from historically minoritized groups entering STEM education, there is insufficient research within the categories of teacher-student relationships and systemic influences. This literature review addresses this gap in the literature by exploring how teacher-student relationships impact students' STEM 
experiences, followed by a brief discussion about systemic influences on the STEM experiences of underserved populations. Kubat (2018) suggests that with typical problem-solving techniques, it is essential to understand how and why students become interested in a STEM career before attempting to address the shortage represented within the STEM workforce. While many studies focus on improving the number of high school students interested in STEM programs, there are not many holistic plans at the high school level that address teacher-student relationships and systemic influences.

Embedded in the following literature review are peer-reviewed articles based on theory and experimental studies addressing teachers and systemic influences as impactful factors of historically underrepresented populations in STEM courses. The examination of current literature corroborates the associations between systemic impacts and teachers' impact as primary stimuli for students enrolling in and participating in STEM programs. In what follows, the discussion about systemic effects is discussed in terms of and teacher impact is discussed with respect to: (1) Inadequate preparation of teachers, (2) teacher-student relationships, (3) teacher recruitment of students, and (4) teacher's perception of STEM. The central ideas of systemic impact include lack of resources and teacher preparation as the reasons why marginalized groups, including Blacks, Latinxs, and women, are historically underrepresented in STEM programs. Implications of this review could help inform and encourage teachers to change traditional strategies and promote an increase in individuals' participation from underrepresented demographics in STEM programs.

\section{Systemic Biases Influence STEM Participation of Historically Marginalized Students \\ Economic Factors}

Systemic influence can be described as the coordination of all attributes within a system that encourages or discourages behaviors, beliefs, actions, or experiences. Systemic influences on the STEM choices of students include access to all the necessary resources for successful STEM education, including buildings, learning materials, technology, funds, and even the quality of teachers. There is an abundance of data that proves that there are disparities within White communities' resources than those of Black and Latinx communities. As a result of these disparities in accessible resources in communities serving predominantly Black and Latinx students, the overall STEM education of far too many Black and Latinx students are negatively influenced. 
Systematically, in many areas within the United States, school district lines are strategically drawn to separate populations of people, and as a result, many schools are separated based on race, wealth, or a combination of the two. For example, many district borders are created to separate students from historically minoritized groups as well as students who live in poverty from the wealthy and White middle class (Fitzgerald, 2015). The separation of populations based on wealth or race contributes to many issues, especially within impoverished communities. For example, McKenzie (2019) found that a predictor of students' academic achievement is their socioeconomic status.

As a result of the systemic influence, an imbalanced cycle is created (see Figure 1). The chart below describes a cycle in which a family's income impacts where they live. In return, it determines their housing (Ostrander, 2015) and school placement, which determines the quality of resources and teachers, resulting in students' educational success and a direct connection between education and adult outcomes, such as earnings, resulting in lower educational quality for students (Johnson \& Tanner, 2018).

\section{Figure 1:}

Continuous Cycle of Poverty and Education

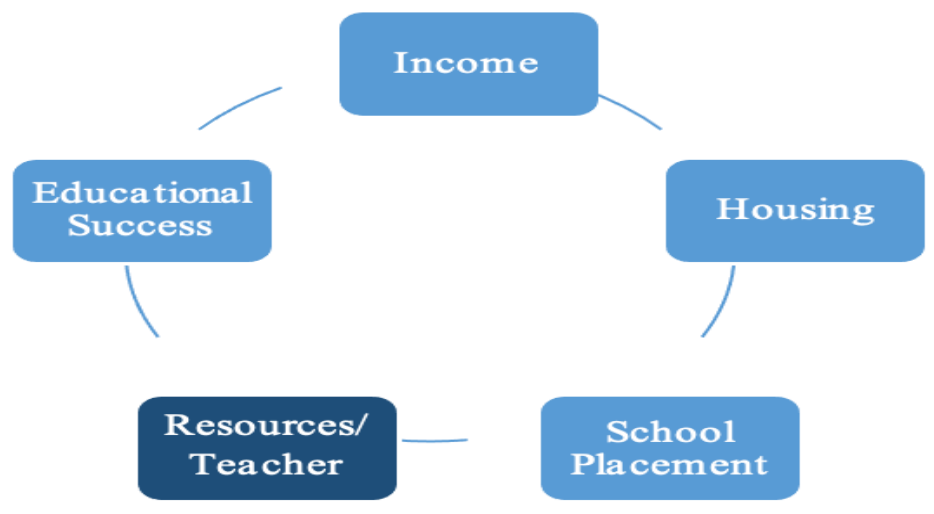

\section{Inequitable Race-based Experiences}

Beyond education within the school, many students from underrepresented demographics do not have access to as many quality learning opportunities outside of the school to spark their interests in STEM careers as their peers (McCullough, 2019). Students living in more impoverished areas, or historically minoritized populated areas, have to travel outside of their communities to obtain quality STEM instruction and pay, usually a large sum of money, to enroll in these programs. Fitzgerald (2015), 
maintain that districts in weak states are subsequently unable to provide the same resources and academic opportunities. As a result of these systemic issues, students of the female population and Black or Hispanic students drop out of STEM programs or avoid them altogether.

Consequences of historical and current race-based disparities suffered by Black and Latinx populations in the United States (U.S.) remain visible, particularly in far too many schools serving predominantly Black and Latinx students. For many of these schools, evidence of race-based disparities can be seen in terms of students' minimal access to STEM resources, including support for building STEM efficacy, identity, and interest (Burt et al., 2020). To better understand race-based systemic practices and how it matters in the STEM experiences of Black and Latinx students, the authors briefly discuss some historical and contemporary educational experiences of Black and Latinx students. Historically, U.S. education of Black and Latinx students has been overtly marked by academically incongruent pedagogical practices that work to minimize the inclusion and support of historically marginalized populations such as Black and Latinx students in STEM (Burt et al., 2020; Collins, 2018). Even as the U.S. began to focus on competing globally by improving the STEM education of its students in K-12, White children and their schools were the primary focus and received appropriate funding (Darling-Hammond, 2010; Ostrander, 2015). Black and Latinx children were not envisioned as part of the focus on strengthening students' STEM education. For Black and Latinx students, their educational experiences involve access to poor quality instructional materials, limited resources, and limited, if not inadequate, pedagogical and curricular methods incongruent with their culture.

In terms of contemporary experiences, clear disinterest in the educational needs of African American students continues as more than 20 states in the U.S. have significantly fewer resources for Black children and their schools on every tangible measure including class sizes, textbooks, computer, facilities, and curriculum offerings (Burt et al., 2020; DarlingHammond, 2010). This disinterest in the academic needs of Black and Latinx students leads to a decreased student access to rich STEM experiences and less cognitively demanding instruction. Unfortunately, students who receive less cognitively demanding and rigorous courses at the onset of their academic career are least likely to choose STEM pathways (Collins, 2018). If these troubling trends continue as academic trajectories for Black and Latinx children, they will continue to diminish access to rigorous STEM experiences. With restrictions to rich high school STEM experiences, national and global repercussions exist, including limited opportunities for Black and 
Latinx children to engage in future STEM careers such as mathematics, mathematics education, engineering, computer sciences, and business ownership, to name a few.

\section{Unfair Policies}

The examination of how unfair policies yield a myriad of negative consequences for schools serving majority Black and Latinx students has been well documented (Adamson \& Darling-Hammond, 2012; Ani, 2013; Baird, 2012; Burt, et al., 2020; Dotson \& Foley, 2016; Fernandes, et al., 2016; Gay, 2013; Ladson-Billings, 2006; McKown, 2013; Ostrander, 2015). Collectively, these studies point to the fact that students attending predominantly Black and Latinx schools are typically caught in a system whose inequitable policies exacerbate historical inequities. From poor quality instructional materials (Ani, 2013; Fernandes et al., 2016; McKown, 2013), inequitable funding (Adamson \& Darling-Hammond, 2012; Dotson \& Foley, 2016), limited resources (Baird, 2012; Burt et al., 2020), and pedagogical and curricular methods that are incongruent with their culture and learning styles (Gay, 2013; Ladson-Billings， 2006; McKown， 2013; Ostrander, 2015) Black and Latinx students continue to experience unequal K-12 schooling.

Funding can be an example of these disparities. For instance, disadvantaged students who attend our nation's highest-poverty schools historically interact with federal, state, and local agencies in order to gain funding through Federal Title I Grants. Title I of the Elementary and Secondary Education Act of 1965 is the U.S. government's largest educational program designed to assist disadvantaged youth. However, it has been reported that many districts in high-need low-SES communities do not receive equitable funding from their local and state governments. Traditionally, Title I allocations to Local Education Agencies (LEAs) are based on the number of eligible children and the per-pupil cost of education.

According to the National Center for Education Statistics (NCES, 2019), because each of the federal allocation formulas uses a series of provisions, there is not a direct link between the percentage of formulaeligible children in a district or state and the percentage of federal funds allocated to that district or state. Furthermore, there is no direct link between the formula-eligible children upon whom the distribution of funds is based and the children who receive services from Title I. Today, about $95 \%$ of children served by Title I funds receive services in schoolwide programs that serve all children in the school, regardless of whether they are formula eligible or not. This means, about 25 million students in U.S. schools receive Title I 
services. Clearly, the spirit and intent of Title I is to support schools serving historically underprivileged students in our nation's highest-poverty schools.

However, because LEAs also receive Title 1 funding through competitive grant programs stemming from No Child Left Behind Act of 2001 (NCLB), and Race to the Top (RT3) initiatives, schools serving historically disadvantaged students receive inequitable funding as they lack the necessary scholastic access and opportunities to compete with their privileged counterparts. According to the U.S. Department of Education, Institute of Education Sciences, National Center for Education Statistics (2018) report $91.7 \%$ of school funding comes from local and state monies. This means that current residential segregation, as discussed in the previous section about economic factors as systemic influences, present opportunities for schools in high-SES school districts serving majority White student populations to receive more funding.

This disparity in funding is clearer when we consider that each year, NCLB and RT3 grants serve over 22 million students and influence the teachings of over 1.5 million teachers in more than 40,000 schools (DarlingHammond, 2010). Initiatives from NCLB and RT3 allow states to improve their chances of obtaining funds by adopting shared education standards with other states. States that agree to compete for NCLB and RT3 funding are allocated monies based on their students' performance on standardized tests and their implementation of enrichment programs. For example, according to the National Assessment of Educational Progress (NAEP) data, in FY 15 alone, the Department of Education awarded \$28.5 million to schools with Advance Placement programs (NAEP, 2017). At the surface, this seems unproblematic. However, an examination of the subtractive schooling experiences of schools serving large amounts of historically marginalized students, such as Black and Latinx students, shows evidence that many of those schools don't have Advance Placement programs and therefore would not receive that award (Ford \& King, 2014).

\section{Teachers Influence STEM Participation of Historically Marginalized Students}

Inadequate preparation of teachers

A significant concern that impacts the under-representation of Blacks, Latinxs, and female students in STEM education is the inadequate preparation of teachers and limited access to STEM resources, especially in Black and Hispanic communities. Now although teacher preparation and access to STEM resources are undoubtedly systemic issues, these issues impact how teachers influence students' take up rates in STEM. With district 
borders being a method of separating students, funds such as property taxes and donations significantly impact the educational system. Taxes from wealthier areas are distributed to the affluent schools; in opposition, the property taxes from more impoverished communities go to underprivileged schools. This disparity in wealth distribution creates a cycle that allows wealthy schools to obtain increased revenue, enabling the school to purchase sufficient equipment and resources. Still, schools within more deprived areas do not have that luxury. This information is essential as it addresses the disparities in teacher preparation and available resources to students within the different communities. Ingersoll et al. (2019) found that the achievement gap and occupational outcomes for Black and Hispanic students emanate from the likelihood that these students will have unequal access to qualified teachers and educational resources.

Beginning with teacher preparation, Brown and Rodriguez (2017) found that White educators, teachers who grew up in predominantly Caucasian neighborhoods, and those who grew up in middle-class families are unprepared to teach students within urban schools composed of lowincome children of color. This lack of teacher preparation derives from the teachers' ability to empathize and connect with minoritized students, their preconceived notions of these students, or strict teachers' lack of educational practice. To correlate the lack of teacher preparation to STEM education, students' perceptions of teachers will inhibit them from attempting STEM courses, especially if there are no teachers, they feel comfortable with or teachers from minoritized groups. Furthermore, in many circumstances, minoritized students fear that they will be stereotyped against or will not relate well with the teacher, especially within STEM courses due to the scarcity of other students from historically minoritized populations. Consequently, many minoritized students desire to enroll in courses which are taught by teachers from historically minoritized groups due to the perception that these teachers will serve as a role model, relate better with them, and the students are more comfortable within these courses because there are not pressures of defending stereotypes that teachers from non-minoritized groups may have about them (Ingersoll et al., 2019).

Due to the lack of teachers from historically minoritized groups such as Blacks and Latinx within the STEM field, students from minoritized groups do not have many options for teacher choice and usually opt to take other courses. Grissom et al. (2017) found that the increased representation of Black and Hispanic teachers within the school increased Black and Hispanic gifted students' representation. There is a lack of data to support teachers' race concerning students' enrollment in STEM courses. Still, various data reports 
and literature supports the conclusion that there is a correlation between teachers from minoritized groups and student course enrollment and student achievement. As a result of the lack of students from historically minoritized populations within the field and differences between background knowledge of students from different ethnic backgrounds, teachers must find a way to cater their instruction to meet the needs of these students. Elliott (2015) advocates that, to efficiently reach and educate students from underrepresented populations, teachers must be trained to integrate strategies that connect the content to the background knowledge of these students.

Not only is it a common theme that many teachers are ill-prepared to instruct students from historically minoritized groups, but many are also illprepared to teach STEM content, especially in culturally diverse schools. For example, Elliott (2015) found that Black students are four times more likely, and Hispanics are two times more likely to be served by the teachers who have not entirely met the state certification and licensing requirements than their White counterparts. The combination of the lack of ability and knowledge of teachers (Darling-Hammond, 2010) has enormous implications regarding students from minoritized groups, such as Blacks and Latinx, continuing in STEM education. While STEM education is an interaction of four disciplines, a blocking factor for implementing an effective STEM program is insufficient teacher knowledge (Timur et al., 2019). As a result, it obstructs minoritized students' desires to stay within these programs.

\section{Teacher-student relationships}

Teacher-student relationships can be defined as teachers' enhanced abilities to significantly motivate students, encourage students' beliefs, and ultimately having a lifelong influence on students' choices. Timur et al. (2019) concluded that, since teachers are often role models to their students, they play a vital role in shaping students' interests in particular subject matters, ultimately persuading students' future career choices. Teachers have a substantial influence on whether or not students will enroll in STEM-related courses regarding STEM education. They influence students' desire to enroll in these programs. Still, teachers are also the driving force of students completing STEM pathways and ultimately pursuing further education and STEM-related careers.

Teachers' influence on students can be constructive or deleterious; either way, the impact is immense. For a typical day, high school students experience average about six hours of sitting time within a classroom. Adding this amount of time over a semester or school year amounts to students spending a considerable amount of time with their teachers. This amount of 
time allows students and teachers to make connections and build influential relationships in students' lives. The relationships that are fostered seem to be either positive or negative, and as a result, teachers can alter students' feelings towards a particular subject. Lyon et al. (2012) argue that young people who are least likely to get involved with STEM participate in those opportunities based on their relationships rather than workforce development goals.

Ultimately, since STEM courses are elective courses, students choose to enroll in classes based on the perceived relationships that they could have with their teachers. As a result, students make inferences about whether they will take particular courses based on the teacher who teaches the class. All too often, students avoid particular courses not because they dislike the topic but as a product of how they feel about the teacher who teaches the subject. Woodward (2018) found that relationships between Black male and their teachers are often entrenched in a foundation of beliefs that these students are nonchalant about education and are not hard workers. As a result, teachers express low expectations for these students, even if they were deemed academically successful. The students within the study also attributed not wanting to take individual teachers' courses because the teachers treat students differently based on their race. Based on these studies, it is evident that the relationships fostered between students and teachers greatly impact the decreased number of students interested in STEM programs, especially within underrepresented populations.

Beyond direct teacher-student relationships, teachers have an indirect influence on students as well. Indirect influence is teachers' ability to stimulate students' feelings or beliefs through sharing their perceptions and demonstrating indirect actions. Preconceived perceptions could be an obstacle to recruitment in STEM (Marchut, \& Gormally, 2019). The theoretical indirect influences in which female, Black, and Hispanic students are motivated to join or avoid STEM are teachers' knowledge and teachers' perceptions.

\section{Teacher Recruitment of Students}

Teachers' ability or inability to understand STEM concepts ultimately has a tremendous impact on students and whether students decide to enter STEM programs and complete STEM pathways. For starters, STEM educators are responsible for advertising their courses to students to increase program enrollment. Consequently, teachers need to comprehend the significance of promoting their practices and make a conscious effort to endorse their courses (Prendergast et al., 2018). Since marketing is vital in increasing student enrollment into STEM courses, teachers must have a vast 
knowledge of STEM concepts to enhance marketing strategies for Blacks and Latinx students.

When teachers are well-versed in STEM education, they ultimately understand how to cater to diverse populations' marketing strategies. The issue with STEM education regarding marketing, a large amount of STEM course material does not include equitable representations of success stories that have individuals outside of the traditional STEM population. The result of the lack of diversity in STEM success stories is students' perception that they do not fit the mold of what it takes to be successful within the STEM field. When teachers present STEM materials using gender and racial relevant contexts, the results are encouraging. Using these materials, students obtain greater respect for the content area because it illustrates the subject value and makes STEM more personally relevant to the students (Prendergast et al., 2018). As a result of effective diversified marketing strategies, classrooms of teachers who market well will have student enrollments that reflect the demographics of the school they teach instead of the traditional demographics seen within the field.

Due to the disproportionate data representing the numbers of female and minoritized students within STEM courses, it is evident that marketing strategies fail to effectively target these students or genuinely do not have them in mind. Students from historically minoritized groups and females are not interested in these courses from the start, and without effective marketing strategies, these students will continue to opt out of taking STEM courses. To combat the lack of minoritized students' motivation to enroll in STEM courses, teachers must educate them on STEM, the benefits of the content and make students feel that STEM is relevant in their lives.

Beyond sustaining Black and Latinx students' interests to take up STEM courses, educators must understand and utilize methods that will encourage students to complete STEM pathways. It is equally important that educators motivate students beyond the course and encourage them to continue within the field after the pathway completion. A significant problem that is seen throughout is that even when female, Black, and Hispanic students enter STEM courses, it is unlikely that these students' interests remain throughout the totality of the STEM program. These students are less likely to complete the program and pursue a degree or career within the field. Means et al. (2018) claim that the probability is more significant for Asian and White males to complete a high school STEM program and continue into a STEM major in college than students from historically marginalized populations such as Blacks and Latinx students. 
As with the issues found within the marketing of STEM programs, there usually are not enough motivational factors that are race or genderspecific to these underrepresented populations to encourage these individuals to continue through the program. Since STEM courses are traditionally electives, meaning that students choose to enroll in these courses, they can also opt out of taking additional courses within the STEM pathway. As a result of students having different STEM course expectations than their core courses, STEM teachers are conflicted between making these courses desirable and ensuring significant STEM learning (Coad, 2016).

\section{Teachers' Perception of STEM}

Just as teachers' relationships with students significantly impact students from historically minoritized groups, such as Blacks and Latinx, and female students entering STEM courses, teacher perceptions about STEM have a similar effect as these perceptions greatly influence how students see STEM. Coad (2016) states that experiences from their educational history influence teachers' perceptions of education. Likewise, students' perceptions stem from their educational experiences as well. To clarify, teachers' perceptions in reference to Black, Latinx, and female students hinder the enrollment and re-enrollment of these populations in STEM classes. Hamilton et al. (2015) assert that unfavorable perceptions based on race, ethnicity, or gender contribute to the classification of students' educational attainment.

In general, the STEM field is dominated by students who are White males (Hamilton et al., 2015). This disparity encourages students of other demographics to not be as successful as their counterparts within STEM courses. Since teachers' perceptions of direction and teaching methods, teachers' perception of STEM education is an essential factor in encouraging underrepresented populations to join STEM courses (Timur et al., 2019). Joshi et al. (2018) found that it is common in the educational field that teachers make more resources and support available to the students of the same race. As a result of these standard practices, based on teachers' perceptions, minoritized students tend to avoid courses where they feel that they will not get as much attention and support as other students do within the class.

Teachers also assume that the requirements for students' success within STEM courses include being highly intelligent and having to maintain a high level of success in their math and science classes (Wang \& Degol, 2017). As a result of this perception regarding STEM students' grades in math and science usually consider a method to enroll students and predict whether they will be successful within STEM courses. Based on the pretense that 
success within core classes directly correlates to the success in STEM-related courses, students' self-efficacy regarding STEM education is negatively impacted. Stubbs \& Myers (2016) concluded that circumstantial evidence influences students' self-efficacy, belief, outcome expectations, interests, goals, and decision-making. Though this theory influences all students' efficacy, current data show disparities in achievement of students from historically marginalized populations, which supports the belief that minoritized students are negatively impacted at a higher rate.

Though there are gaps within the literature of the theory of teachers' perspectives of STEM directly impacting the self-efficacy of minoritized students at a higher rate than White students, the analysis of achievement data and literature analysis permits veracity to the association. Achievement data consistently depicts the general scores of students from historically minoritized groups such as Blacks and Latinx students, being suspiciously lower than White students. Koon \& Davie (2019) found that Black students are disproportionately less successful in math and science courses, and that achievement gaps are evident with the students from dual-language families (Prendergast et al., 2018) are compared to their White counterparts. These academic performances of Black and Latinx students are unsurprisingly a result of long standing inequitable and historical practices of subtractive schooling experiences. Combining this data with the current literature analyses permits the interpretation that minoritized students' self-efficacies are negatively impacted by teachers' perceptions beyond White males' measures. As a result of the perception of math and science being predictors of student success within STEM courses, students from historically minoritized groups, such as Blacks and Latinx, have an enhanced fear that their mediocre grades will not allow them to succeed in STEM programs and avoid STEM courses altogether.

Perception about STEM extends beyond race and can be seen in many gender-based STEM demographics as well. According to Karisan et al. (2019), female teachers' confidence levels were inferior to that of males as it pertained to technology (2019) and teachers' confidence levels become manifested within the characteristics of student observers. The stereotype threat is posing a great concern for girls who might desire to enter STEMrelated courses. The stereotype also highlights another important factor in the STEM choices of Black and Latinx students. The intersectionality of race and gender is another impactful factor in the STEM experiences of Black and Latinx students. McCullough (2019) posits that females' interest in STEM programs remains high, but many women are reluctant to enroll due to the common misconception that STEM programs and careers are for males. 
Coupled with the stereotype of being incapable of achieving at the same level as their male counterparts in the field many women often feel intimidated (McCullough, 2019). In fact, the stereotype threat intensifies the deprivation of females being comfortable within STEM courses. As a male-dominated field, far too many women unconsciously perform to the stereotype. This gender stereotype threat enhances female students' reluctance to enter the STEM field, especially if they are Black or Hispanic.

\section{IMPLICATIONS AND CONCLUSION}

Implications of this review could help inform and encourage teachers to change traditional strategies and stimulate an increase in individuals' participation from underrepresented demographics in STEM programs. Although current literature implicates students' self-efficacy, students' interests, and familial background as reasons for the underrepresentation of Black, Latinx, and female students within STEM education, this paper implicates teachers' impact and systemic influences as critical factors. Undeniably, teachers are incredibly influential in the success, interest, and eventual enrollment of Black, Latinx, and female students in STEM programs. To increase the high school STEM choices of these historically underrepresented students in STEM with steady registration of these populations in STEM courses, teachers and educational leaders must revamp their marketing strategies with these student demographics.

With the enrollment of White and Asian subgroups in STEM courses remaining high (Hamilton et al., 2015), there needs to be a rethinking of current approaches to improving the STEM take up rates of Black and Latinx students. The problem with current marketing strategies of STEM education for Black and Latinx students is the overall perception of STEM education. That is, based on the stereotype threat that holds White males and Asian students as the successful STEM students, far too many Black and Latinx students develop negative identities in subject areas necessary for STEM pathways such as mathematics (Aguirre et al., 2013; Basque \& Bouchamma, 2016; Martin 2013). While there is a deficiency of research in teachers' perceptions impacting students' perceptions within the STEM curriculum, comprehensive examinations and analysis of teachers' perceptions from other curriculum have theoretical and practical significance (Stubbs \& Myers, 2019). Although Caucasian males dominate STEM courses, and fluency in mathematics and science is beneficial, these characteristics are not predictors of STEM success. Wang \& Degol (2017) found that a student being proficient in math and science does not automatically prepare the student to be 
successful in STEM-related activities or even appreciate the subject enough to pursue a STEM career. In short, educational leaders must also understand that the successes in general education courses are not predictors of success within STEM courses.

Current literature concludes that there is a correlation between SAT and ACT scores. It was found that students who achieved too high or perfect scores on the SAT/ACT were likely to have high successes within the STEM curriculum (Vu et al., 2019). The information that is absent from the literature is the opposing side of whether lower ACT/SAT scores directly correlate to student achievement in STEM programs. In close relation to ACT/SAT achievement, research has concluded a relationship between mathematics and science grades as potential predictors of success within STEM courses (2019). There is an issue with this verdict as math and science scores concerning STEM success are scarce.

Beyond the traditional perceptions of STEM, stereotype threat is another deterrent that diminishes Black, Hispanic, and female students' desire to enroll in STEM courses. Negative stereotypes and lowered expectations undermine their academic performance and add extra stress to these students (Elliott, 2015). To solve the problems associated with stereotype threat, teachers must incorporate diverse populations within their teachings. With over $70 \%$ of teachers throughout America being of European descent, stereotype threat has a massive impact on students from historically marginalized groups (Fox, 2016). Additionally, the increased diversity in teachers that instruct STEM courses has proven beneficial. Though more information about this topic is needed, the successful application of the information within this literature will significantly impact high school students from historically minoritized groups such as Blacks and Latinx and female students in STEM programs.

\section{REFERENCES}

Adamson, F., \& Darling-Hammond, L. (2012). Funding disparities and the inequitable distribution of teachers: Evaluating sources and solutions. Disparidades de Financiamento e a Desigual Distribuição de Professores: Avaliando fontes e soluções., 20(37), 1-42.

Aguirre, J. M., \& del Rosario Zavala, M. (2013). Making culturally responsive mathematics teaching explicit: A lesson analysis tool. Pedagogies, $8(2)$, $163-190$.

Ani, A. (2013). In spite of racism, inequality, and school failure: Defining hope with achieving black children. Journal of Negro Education, 82(4), 408-421.

Baird, K. (2012). Class in the classroom: The relationship between school resources and math performance among low socioeconomic status students in 19 rich 
countries. Education Economics, 20(5), 484-509. doi:10.1080/09645292.2010.511848

Basque, M., \& Bouchamma, Y. (2016). Predictors of Mathematics Performance: The Impact of Prior Achievement, Socioeconomic Status and School Practices. International Studies in Educational Administration (Commonwealth Council for Educational Administration \& Management (CCEAM)), 44(1), 85-104.

Brown, T. M., \& Rodriguez, L. F. (2017). Collaborating with urban youth to address gaps in teacher education. Teacher Education Quarterly, 44(3), 75-92. https:/files.eric.ed.gov/fulltext/EJ1149098.pdf

Burt, B. A., Stone, B. D., Motshubi, R., \& Baber, L. D. (2020). STEM validation among underrepresented students: Leveraging insights from a STEM diversity program to broaden participation. Journal of Diversity in Higher Education. Advance online publication. http://dx.doi.org/10.1037/dhe0000300

Burrows, A., Lockwood, M., Borowczak, M., Janak, E., \& Barber, B. (2018). Integrated STEM: Focus on informal education and community collaboration through engineering. Education Services, 8(4), 1-15. https:/files.eric.ed.gov/fulltext/EJ1174955.pdf

Coad, L. (2016). The M in STEM what is it really? Australian Mathematics Teacher, 72(2), 3-6. https://eric.ed.gov/?id=EJ1106797

Collins, K. H. (2018). Confronting color-blind stem talent development: Toward a contextual model for black student stem identity. Journal of Advanced Academics, 29(2), 143-168. doi:10.1177/1932202X18757958

Darling-Hammond, L. (2010). The flat world and education: How America's commitment to equity will determine our future. New York, NY: Teachers College Press.

Dotson, L., \& Foley, V. (2016). Middle grades student achievement and poverty levels: Implications for teacher preparation. Journal of Learning in Higher Education, 12(2), 33-44.

Elliott, K. (2015). Broadening participation - Making STEM learning relevant and rigorous for all students. Community for Advancing Discovery Research in Education

(CADRE). https://eric.ed.gov/?q=source $\% 3 \mathrm{~A} \% 22$ community+for+advancing+discove ry+research+in+education \%22\&id=ED590453

Fernandes, R., Ha, I., McElroy, S., \& Myers, S. (2016). Black-white disparities in test scores: Distributional characteristics. Review of Black Political Economy, 43(2), 209-232. doi:10.1007/s12114-015-9230-5

Firat, E. A. (2020). Science, technology, engineering, and mathematics integration: Science teachers' perceptions and beliefs. Science Education International, 31(1), 104-116. doi:10.33828/sei.v31.i1.11

Fitzgerald, T. (2015). White racial framing related to public school financing. Forum on Public Policy Online, 2015(1), 1-23. https://eric.ed.gov/?q=White+racial + frame\&pr $=$ on $\& \mathrm{ft}=$ on\&id $=\mathrm{EJ} 1080937$ 
Ford, D. Y., \& King, J. R. A. (2014). No Blacks allowed: Segregated gifted education in the context of Brown v. Board of Education. Journal of Negro Education, 83(3), 300-310.

Fox, L (2016). Seeing potential: The effects of student-teacher demographic congruence on teacher expectations and recommendations. AERA Open, 2(1), 1-17. https://doi.org/10.1177/2332858415623758

Gay, G. (2013). Teaching to and through cultural diversity. Curriculum Inquiry, 43(1), 48-70. doi:10.1111/curi.12002

Grissom, J. A., Rodriguez, L. A., \& Kern, E. C. (2017). Teacher and principal diversity and the representation of students of color in gifted programs: Evidence from national data. The Elementary School Journal, 117(3), 396422. https://doi.org/10.1086/690274

Hamilton, A. F., Malin, J., \& Hackmann, D. (2015). Racial/ethnic and gender equity patterns in Illinois High School Career and Technical Education coursework. Journal of Career and Technical Education, 30(1), 29-52. https://files.eric.ed.gov/fulltext/EJ1085015.pdf

Idin, S. \& Donmez, I. (2018). A metaphor analysis study related to STEM subjects based on

middle school students' perceptions. Journal of Education in Science, Environment and

Health (JESEH), 4(2), 246-257. doi:10.21891/jeseh.453629

Ingersoll, R., May, H., \& Collins, G. (2019). Recruitment, employment, retention and the minority teacher shortage. Education Policy Analysis Archives, 27, 37. https://doi.org/10.14507/epaa.27.3714

Johnson, R. C., \& Tanner, S. (2018). Money and freedom: The impact of California's school finance reform on academic achievement and the composition of district spending. Policy Analysis for California Education, PACE, 70(3), 1-63. https://files.eric.ed.gov/fulltext/ED594733.pdf

Joshi, E., Doan, S., \& Springer, M. G. (2018). Student-teacher race congruence: New evidence and insight from Tennessee. AERA Open, 4(4), 233285841881752. https://doi.org/10.1177/2332858418817528

Karisan, D., Macalalag, A., \& Johnson, J. (2019). The effect of methods course on preservice teachers' awareness and intentions of teaching science, technology, engineering, and mathematics (STEM) subjects. International Journal of Research in Education and Science (IJRES), 5(1), 22-35.

Koon, S., \& Davis, M. (2019). Math course sequences in grades 6-11 and math achievement in Mississippi. Regional Educational Laboratory Southeast. https://eric.ed.gov/?id=ED597299

Kubat, U. (2018). The integration of STEM into science classes. World Journal on Educational Technology: Current issues, 10(3), 165-173. https://doi.org/10.18844/wjet.v10i3.3557

Ladson-Billings, G. (2006). From the achievement gap to the education debt: Understanding achievement in U.S. schools. Educational Researcher, 35(7), $3-12$. 
Lyon, G. H., Jafri, J., \& St. Louis, K. (2012). Beyond the pipeline: STEM pathways for youth development. Afterschool Matters. https://eric.ed.gov/?id=EJ992152

Marchut, A. E., \& Gormally, C. (2019). Successes and limitations of inquiry-based laboratories on affective learning outcomes for deaf, hard-of-hearing, and hearing signing students. Journal of the Scholarship of Teaching and Learning, 19(4). https://doi.org/10.14434/josotl.v19i4.24469

Mau, W. C., Chen, S. J., \& Lin, C. C. (2019). Assessing high school student's STEM career interests using a social cognitive framework. Education Sciences, 9(2), 151. https://doi.org/10.3390/educsci9020151

McCullough, L. (2019). Proportions of women in STEM leadership in the academy in the USA. Education Sciences, 10(1), 1. https://doi.org/10.3390/educsci10010001

McKown, C. (2013). Social equity theory and racial-ethnic achievement gaps. Child Development, 84(4), 1120-1136. doi:10.1111/cdev.12033

Means, B., Wang, H., Wei, X., Iwatani, E., \& Peters, V. (2018). Broadening participation in STEM college majors: Effects of attending a STEM-focused high school. AERA Open, 4(4). https://doi.org/10.1177/2332858418806305

National Center for Education Statistics (2018). Revenues and Expenditures for Public Elementary and Secondary Education: School Year 2015-16 (Fiscal Year 2016). Retrieved from https://nces.ed.gov/pubsearch/pubsinfo.asp?pubid=2019301

Ostrander, R. R. (2015). School funding: Inequality in district funding and the disparate impact on urban and migrant school children. Brigham Young University Education \& Law Journal(1), 271-295.

Prendergast, M., Murphy, C., O’Neill, A., \& Roche, J. (2018). Trinity Walton Club: What is its potential for promoting interest in STEM? European Journal of STEM Education, 3(1). https://doi.org/10.20897/ejsteme/83659

Sharp, L. A., Carruba-Rogel, Z., Diego-Medrano, E. (2019). Strengths and shortcomings of a teacher preparation program: Learning from racially diverse preservice teachers. Journal of Teacher Education and Educators, 8(3), 281-301. https://files.eric.ed.gov/fulltext/EJ1240079.pdf

Slovacek, S., Miu, V., Soto, K., \& Ye, H. (2019). Supporting STEM in higher education. International Journal of Education and Practice, 7(4), 438-449. https://doi.org/10.18488/journal.61.2019.74.438.449

Stevenson, H. (2014). Myths and motives behind STEM (science, technology, engineering, and mathematics) education and the STEM-worker shortage narrative. Issues in Teacher Education, 23(1), 133. https://files.eric.ed.gov/fulltext/EJ1045838.pdf

Stubbs, E. A., \& Myers, B. E. (2016). Part of what we do: Teacher perceptions of STEM integration. Journal of Agricultural Education, 57(3), 87-100. https://www.jae-online.org/attachments/article/1993/2016-3-06-Stubbs.pdf 
Timur, S., Timur, B., \& Çetin, N. I. (2019). Effects of STEM based activities on inservice teachers' views. Educational Policy Analysis and Strategic Research, 14(4), 102-113. https://doi.org/10.29329/epasr.2019.220.6

U.S Department of Labor, Bureau of Labor Statistics. (2021). Budget analyst. Occupational

Outlook

Handbook. Retrieved from https://www.bls.gov/emp/tables/stem-employment.htm

Vu, P., Harshbarger, D., Crow, S., \& Henderson, S. (2019). Why STEM? Factors that Influence Gifted Students' Choice of College Majors. International Journal of Technology in Education and Science, 3(2), 64-71.

Walcott, J.R. (2019). Urban-focused teacher preparation in liberal arts colleges and universities: Confronting the challenges. AILACTE Journal 16, 1-24.

Wang, M., Degol, J.L. (2017). Gender gap in science, technology, engineering, and mathematics (STEM): Current knowledge, implications for practice, policy, and future directions. Educ Psychol Rev 29(1), 119-140. https://doi.org/10.1007/s10648-015-9355-x

Agyekum, S. (2019). Teacher-student relationships: The impact on high school students. Journal of Education and Practice. https://www.iiste.org/Journals/index.php/JEP/article/view/48078

MICHAEL OWENS, EdS, is an assistant principal of a middle school within the United States and a graduate student at the University of West Georgia. His major research interests lie in the area of secondary education, inequities in education, Science Technology Engineering Math (STEM), higher education research and multiculturalism. Email: Owensjrm@gmail.com

NATASHA N. RAMSAY-JORDAN, EdD, is an Assistant Professor in the Department of Early Childhood through Secondary Education at the University of West Georgia. Her major research interests lie in the area of mathematics education, STEM education, education policies, issues of diversity, equity, access, and inclusion in education, culturally responsive pedagogy, and the role of culture in mathematics education and development. Email: nrjordan@westga.edu 